Published online: April 4, 2007

\title{
Education in the United States: Is it a Black Problem?
}

\author{
Eddie Comeaux, and Uma M. Jayakumar
}

\section{ERRATUM TO: THE URBAN REVIEW}

Article DOI: $10.1007 / \mathrm{s} 11256-007-0054-\mathrm{x}$ is a revised version of Article DOI: 10.1007/s11256-006-0031-9 which appeared online July 7, 2006.

The online version of the original article can be found at http://dx.doi.org/10.1007/s11256006-0031-9 Address correspondence to Eddie Comeaux, Graduate School of Education and Information Studies, University of California, Los Angeles, USA; e-mail: ecomeaux@ucla.edu. 